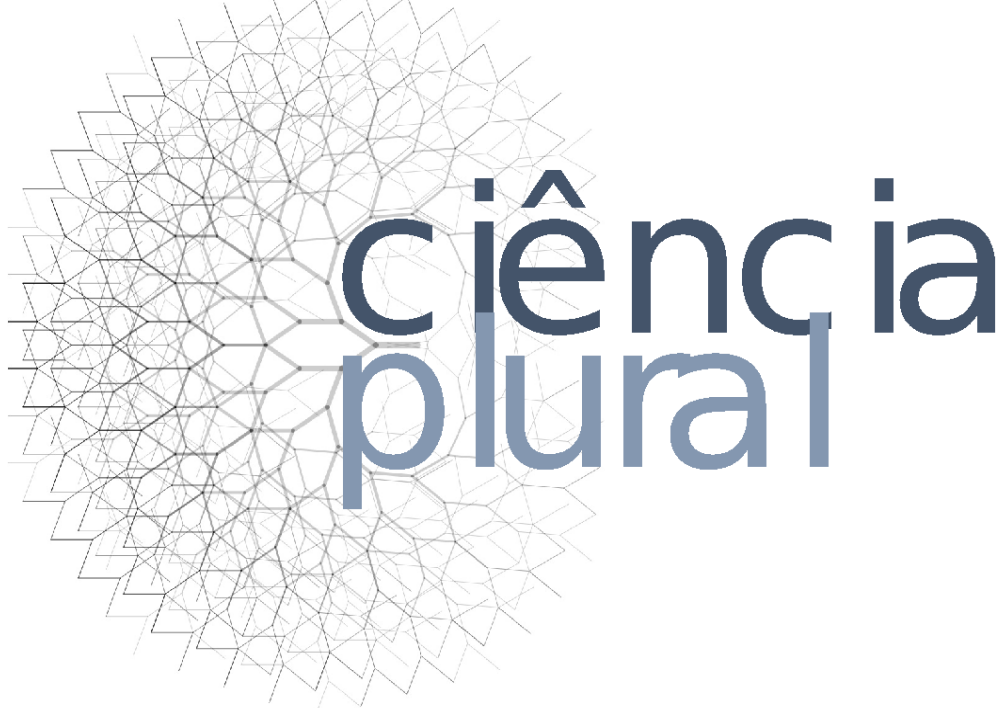

\title{
AÇÕES DE EDUCAÇÃO ALIMENTAR E NUTRICIONAL COM GRUPOS EM VULNERABILIDADE SOCIAL: RELATO DE EXPERIÊNCIA
}

Food and nutritional education actions with social vulnerability groups: experience report

Acciones de educación alimentaria y nutricional con grupos en vulnerabilidad social: informe de experiencia

Nadia Cristina Testoni Chaves Pereira • Acadêmica da graduação em Nutrição da Universidade do Vale do Itajaí-UNIVALI • E-mail: nadiatestoni0@gmail.com Ivana do Nascimento Albuquerque • Acadêmica da graduação em Nutrição da UNIVALI • E-mail: ivana.peixe@gmail.com Kelly Huther da Costa • Acadêmica da graduação em Nutrição da UNIVALI • E-mail: kellycosta29@gmail.com

Patricia Larissa Borges • Acadêmica da graduação em Nutrição da UNIVALI • E-mail: patiy.borgess@gmail.com

Ruan Kaio Silva Nunes • Acadêmica da graduação em nutrição da UNIVALI • E-mail: ruan-kaiio@hotmail.com

Elisabeth Barth Almeida $\bullet$ Mestre em Turismo e Hotelaria-UNIVALI • Docente do curso de Nutrição da UNIVALI • E-mail: bethbarth@univali.com Mariana Reiser Guedes • Mestranda em Saúde e Gestão do Trabalho-UNIVALI • Docente do curso de Nutrição da UNIVALI • E-mail: marianaguedes@univali.com Rosana Henn • Mestre em Ciência dos Alimentos-UFSC • Docente do curso de Nutrição da UNIVALI • E-mail: rhenn@univali.br

Autora responsável pela correspondência:

Nadia Cristina Testoni Chaves Pereira • E-mail: nadiatestoni0@gmail.com 


\section{RESUMO}

Introdução: $O$ aumento da incidência de doenças crônicas não transmissíveis evidencia a necessidade de ações educativas que promovam melhora na qualidade de vida, diminuição da insegurança alimentar e prevenção de agravos nutricionais. Objetivo: Relatar a experiência de um projeto de extensão universitária desenvolvido para estimular a adoção de hábitos alimentares saudáveis e transmitir demais informações relevantes para a autonomia alimentar. Metodologia: $O$ projeto de extensão vinculado ao curso de Nutrição promoveu aplicação de oficinas no decorrer do ano de 2019, realizadas por acadêmicos supervisionados por professores. Os beneficiados foram frequentadores do Centro de Arte e Lazer e Centro de Referência de Assistência Social do município de Itajaí-SC, sendo estes idosos e indivíduos em vulnerabilidade social, respectivamente. Contaram com participação de acadêmicos bolsistas, voluntários e estagiários de Nutrição em Saúde Coletiva, proporcionando a interface ensino e extensão. Os temas abordados foram adaptados de acordo com as demandas de cada local e público específico. Resultados: As oficinas desenvolvidas oportunizaram a vivência de educação alimentar e nutricional a acadêmicos de nutrição, proporcionando ampliação do conhecimento teórico e prático obtido na Universidade com troca de experiências com a comunidade. Conclusão: A oportunidade de atuação em uma extensão universitária proporciona experiências únicas que não são adquiridas dentro da sala de aula. Ela estreita os laços entre universitários e a comunidade, tornando os acadêmicos profissionais aptos a praticar a empatia e sensibilidade social, tão importante ao profissional da saúde. Ainda, favorece a autonomia do indivíduo em relação a alimentação saudável e melhora da qualidade de vida.

Palavras-Chave: Relações Comunidade-Instituição; Educação Alimentar e Nutricional; Vulnerabilidade Social; Educação em Saúde; Promoção da Saúde.

\section{ABSTRACT}

Introduction: The increased incidence of noncommunicable chronic diseases highlights the need for educational actions that promote improved quality of life, decreased food insecurity and prevention of nutritional disorders. Objective: Report the experience of a university extension project developed to encourage the adoption of healthy eating habits and transmit other relevant information for food autonomy. Methodology: The extension project linked to the Nutrition course promoted workshops in 2019, conducted by academics supervised by teachers. The beneficiaries were attendees of the Art and Leisure Center and Reference Center for Social Assistance in the city of Itajaí-SC, being these elderly and individuals in social vulnerability, respectively. Participated by scholarship scholars, volunteers and trainees of Collective Health Nutrition, providing the interface teaching and extension. The topics addressed were adapted according to the demands of each specific location and audience. Results: The developed workshops provided the opportunity to experience food and nutrition education to students of the nutrition course, and through practice, provided the expansion of theoretical knowledge 
obtained at the university with the exchange of experiences with the community. Conclusions: The opportunity to work at a university extension provides unique experiences that are not gained within the classroom. It tightens ties between college students and the community, making academics professionals able to practice the empathy and social sensitivity that is so important to the health worker. Still, it favors the autonomy of the individual in relation to healthy eating and improvement of quality of life.

Keywords: Community-Institucional Relations, Food and Nutrition Education, Social Vulnerability; Health Education; Health Promotion.

\section{RESUMEN}

Introducción: Texto das conclusõe El aumento en la incidencia de enfermedades crónicas no transmisibles resalta la necesidad de acciones educativas que promuevan la mejora de la calidad de vida, la disminución de la inseguridad alimentaria y la prevención de problemas nutricionales. Objetivo: Informar sobre la experiencia de un proyecto de extensión universitaria desarrollado para fomentar la adopción de hábitos alimenticios saludables y transmitir otra información relevante para la autonomía alimentaria. Metodología: El proyecto de extensión vinculado al curso de Nutrición promovió la aplicación de talleres a lo largo de 2019, realizados por académicos supervisados por maestros. Los beneficiarios asistieron al Centro de Arte y Ocio y al Centro de Referencia de Asistencia Social en el municipio de Itajaí$\mathrm{SC}$, siendo estos ancianos e individuos en vulnerabilidad social, respectivamente. Contaban con la participación de becarios, voluntarios y pasantes de Nutrición en Salud Pública, brindando la interfaz de enseñanza y extensión. Los temas cubiertos fueron adaptados de acuerdo a las demandas de cada ubicación y audiencia específica. Resultados: Los talleres desarrollados brindaron la oportunidad de experimentar la educación alimentaria y nutricional para estudiantes de nutrición, proporcionando una expansión del conocimiento teórico y práctico obtenido en la Universidad con un intercambio de experiencias con la comunidad. Conclusiones: la oportunidad de trabajar en una extensión universitaria proporciona experiencias únicas que no se adquieren dentro del aula. Aprieta los lazos entre los estudiantes universitarios y la comunidad, haciendo que los académicos profesionales puedan practicar la empatía y la sensibilidad social, tan importantes para los profesionales de la salud. Aún así, favorece la autonomía del individuo en relación con una alimentación saludable y la mejora de la calidad de vida.

Palabras clave: Relaciones Comunidad- Institucionales, Educación Alimentaria y Nutricional, Vulnerabilidad Social; Educación en Salud; Promoción de la Salud. 


\section{Introdução}

O quadro epidemiológico nutricional da população brasileira advém da coexistência de carências nutricionais e doenças infecciosas, bem como de um gradativo aumento dos índices de Doenças Crônicas Não Transmissíveis (DCNT), como obesidade/sobrepeso em todas as faixas etárias ${ }^{1}$. Sendo este um grande desafio para a saúde pública mundial, pois de acordo com a Organização Mundial da Saúde (OMS), essas doenças tiveram suas taxas de incidência e prevalência aumentadas significativamente nas últimas três décadas².

A importância da segurança alimentar e nutricional é fundamental para prevenção destas patologias, pois consiste na realização do direito ao acesso a alimentos de qualidade, em quantidade suficiente, sem comprometer outras necessidades essenciais. Pressupõe-se que seu alcance implique a convergência de políticas e programas de vários setores com capacidades para promover, na dimensão individual e coletiva, o acesso à alimentação adequada, requerendo um amplo processo de descentralização, territorialização e gestão social ${ }^{3}$. No Brasil, constatou-se que 52 milhões de pessoas vivenciavam a insegurança alimentar em 2015, decorrente da insuficiente garantia ao acesso regular e permanente a alimentos de qualidade, em quantidade necessária, sendo considerado um fator de risco para obesidade ${ }^{4}$.

Considerando o aumento da incidência da obesidade, tem-se fomentado discussões sobre a adoção de ações em saúde, com destaque para a Educação Alimentar e Nutricional (EAN). Nesse sentido, a EAN constitui uma estratégia que incorpora ações de prevenção de agravos, promoção da saúde e controle de problemas alimentares e nutricionais como as DCNT's $\mathrm{s}^{5}$.

Portanto, a extensão universitária proporciona um espaço indispensável às ações de EAN, onde os acadêmicos com auxílio de professores elaboram atividades que visam a promoção da saúde, buscando ofertar oficinas que estimulem a adoção de hábitos alimentares saudáveis, com o intuito de minimizar a insegurança alimentar e nutricional e auxiliar o indivíduo a garantir seu bem-estar e sua qualidade de vida ${ }^{6}$. 
Diante disso, o presente artigo tem o objetivo de relatar a experiência de um projeto de extensão universitária desenvolvido para estimular a adoção de hábitos alimentares saudáveis e transmitir demais informações relevantes para a autonomia alimentar.

\section{Metodologia}

Trata-se de um estudo descritivo, do tipo relato de experiência, no qual foi retratada a rotina do projeto de extensão da Universidade do Vale do Itajaí (UNIVALI) intitulado: "Educação Alimentar e Nutricional na Promoção da Cidadania, da Saúde e Prevenção de Doenças" que é vinculado ao curso de Nutrição e tem por objetivo garantir o acesso a informações e orientações a grupos vulneráveis, de forma contínua, permanente e planejada, por meio da vigilância alimentar e nutricional e de ações educativas no âmbito da alimentação saudável e consequente promoção da cidadania, da saúde e prevenção de doenças.

Foram realizadas ações de EAN no Centro de Arte e Lazer (CAL) e no Centro de Referência de Assistência Social (CRAS) do município de Itajaí-SC, bem como participação em outro projeto de extensão da universidade, intitulado Associação de Afásicos de Itajaí e Região (AAFAS). As atividades realizadas pelo projeto ocorreram no decorrer do ano de 2019, iniciando no mês de março e finalizando em dezembro. As ações foram realizadas duas vezes por semana, no período vespertino, por acadêmicos do curso de Nutrição e bolsistas do projeto e uma vez por semana, no período matutino, por estagiários da disciplina de "Saúde Coletiva", sendo sempre acompanhados por um professor responsável. As ações de extensão desenvolvidas, objetivam estimular a participação acadêmica na problemática social e a integração com diversos setores da sociedade, privilegiando ações interdisciplinares e com maior impacto social, de acordo com as necessidades apresentadas pela própria comunidade.

Os temas abordados em cada encontro foram determinados de acordo com as demandas de cada local e público específico. Os beneficiados eram frequentadores dos CAL e CRAS, sendo estes idosos e indivíduos em vulnerabilidade social, respectivamente. 
Durante todo o período de execução do projeto, realizaram-se reuniões com os acadêmicos voluntários, bolsistas e professores no intuito de definir temas a serem trabalhados. Foram elaborados ainda, materiais utilizados para efetivação das oficinas, tais como cartazes, banners, folders, cartões de ilustração, entre outros materiais manuais, assim como recortes de rótulos de alimentos. Para determinadas ações, foram ofertadas preparações culinárias para degustação, de acordo com o tema proposto, as quais foram preparadas pela professora do curso de Gastronomia no laboratório de técnica dietética da instituição.

No momento da realização das ações, eram coletados dados como número de participantes presentes nos locais e registros fotográficos (preservando a identidade dos participantes). Sendo que, ao final de cada ação, elaboravam-se relatórios das mesmas, a fim de registrar e arquivar os resultados obtidos.

Como forma de contabilizar o número de pessoas beneficiadas direta e indiretamente, método instituído pela universidade, define-se direto como as pessoas as quais estavam presentes nas ações e como indireto aquelas que puderam obter informação, mesmo não estando presentes, considerando que o conhecimento adquirido pelos indivíduos participantes foi repassado às pessoas próximas a ela7.

Foram abordados 13 assuntos distintos por meio de dinâmicas, sendo elas: "Açúcares e gorduras", "Chás", "Alimentação saudável", "Prato saudável”, "Consumo hídrico", "Rótulos alimentares", "Comida de verdade", "Intestino saudável", "Alimentos que melhoram o astral", "PANC's" (Plantas Alimentícias Não Convencionais), “Benefícios da aveia e chia", "Lanches saudáveis" e "Festa junina saudável".

\section{Resultados e Discussão}

De acordo com o Guia Alimentar para a População Brasileira8, a alimentação engloba diversos aspectos, entre eles as dimensões culturais e sociais das práticas alimentares, o modo como os alimentos são preparados e os alimentos que fornecem os nutrientes. A adequada ingestão alimentar é essencial para a manutenção da saúde, 
para tanto, é necessário o olhar abrangente e uma ação que oriente, incentive e promova autonomia para a escolha dos alimentos.

O Quadro 1 apresenta a relação das atividades realizadas no decorrer do ano de 2019, os locais de execução das mesmas e o número de pessoas atingidas direta e indiretamente. Destaca-se que a ação "Comida de verdade" teve maior prevalência de aplicação, sendo empregada em três locais diferentes. Segundo Bezerra et al. ${ }^{9}$ a boa aceitação da equipe pela comunidade é um ponto facilitador para o compartilhamento de saberes. Corroborando com esse fato, Oliveira ${ }^{6}$ afirma que a prática da extensão universitária estreita os laços entre a universidade e a comunidade, aprimorando o profissional para atuar a serviço dela.

Quadro 1. Relação de atividades realizadas e número de pessoas atingidas ano de 2019. Itajaí-SC, 2019.

\begin{tabular}{|c|c|c|c|}
\hline NOME DA AÇÃO & LOCAL & $\begin{array}{l}\text { PÚBLICO } \\
\text { DIRETO }\end{array}$ & $\begin{array}{l}\text { PÚBLICO } \\
\text { INDIRETO }\end{array}$ \\
\hline "Prato saudável" & CRAS e CAL & 47 & 235 \\
\hline "Açúcares e gorduras" & CRAS e CAL & 29 & 145 \\
\hline “Chás" & CRAS e CAL & 51 & 255 \\
\hline "PANC's" & CRAS & 7 & 35 \\
\hline “Alimentação saudável” & CRAS & 10 & 50 \\
\hline "Lanches saudáveis" & CRAS & 20 & 100 \\
\hline "Benefícios da aveia e chia" & CRAS & 12 & 60 \\
\hline "Festa junina saudável" & CRAS & 13 & 65 \\
\hline “Consumo hídrico" & CRAS e CAL & 54 & 270 \\
\hline "Comida de verdade" & CRAS, CAL e AAFAS & 69 & 345 \\
\hline "Intestino saudável" & CRAS & 7 & 35 \\
\hline $\begin{array}{c}\text { "Alimentos que melhoram o } \\
\text { astral" }\end{array}$ & CRAS & 6 & 30 \\
\hline "Rótulos alimentares" & CRAS & 7 & 35 \\
\hline
\end{tabular}




\begin{tabular}{|c|c|c|c|}
\hline $\begin{array}{c}\text { "Aproveitamento integral } \\
\text { dos alimentos" }\end{array}$ & CRAS & 6 & 30 \\
\hline TOTAL PARCIAL & - & 338 & $\mathbf{1 6 9 0}$ \\
\hline TOTAL GERAL & - & \multicolumn{2}{|c|}{$\mathbf{2 0 2 8}$} \\
\hline
\end{tabular}

Legenda: CRAS: Centro de Referência de Assistência Social; CAL: Centro de Arte e Lazer; AAFAS: Associação de Afásicos de Itajaí e Região.

Para a dinâmica "Prato saudável", os participantes foram divididos em grupos e entregues a cada um prato e figuras de alimentos (tanto saudáveis como não saudáveis), para que montassem um prato que consomem no dia a dia. Em seguida, foi exposto um banner ilustrando um prato saudável, parâmetro de uma alimentação balanceada (Figura 1). Por fim, foi explicada a importância de cada grupo alimentar e quantidades adequadas de consumo, respondendo dúvidas dos participantes.

Uma das alternativas para uma alimentação saudável e equilibrada é o consumo de alimentos baseados em vegetais, ou seja, uma alimentação composta por proteínas, gorduras, carboidratos, fibras, vitaminas e minerais, os quais podem ser encontrados nos cereais, frutas, legumes, verduras e carnes ${ }^{10}$. Baseado nisso, a oficina "Prato Saudável" foi aplicada com o intuito de orientar de forma lúdica, educativa e interativa como elaborar um prato saudável, para atender as necessidades nutricionais do indivíduo através da correta proporção dos grupos alimentares. Os participantes demonstraram grande interesse visto que sua percepção de elaborar um prato saudável diferia da aprendida na oficina, além disso, a maneira orientada era de fácil memorização, podendo ser aplicada diariamente sem dificuldades. 

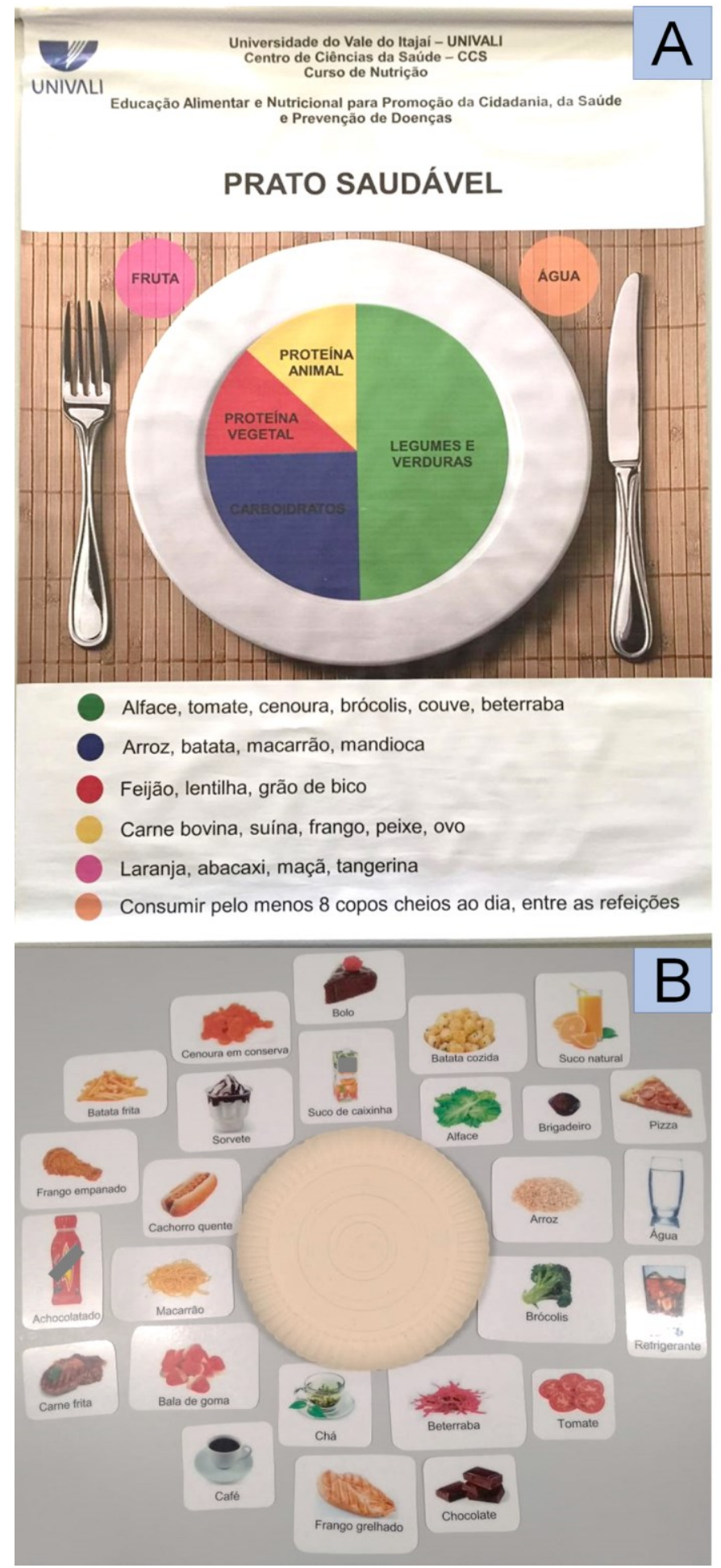

Figura 1. Materiais utilizados para efetivação da dinâmica "Prato saudável". Itajaí-SC, 2019. Legenda: a imagem A ilustra o banner utilizado; a imagem B demonstra o prato e as figuras de alimentos manuseados pelos participantes para montar o seu prato.

Em relação a dinâmica "Açúcares e gorduras", foram mensuradas as quantidades de açúcares e gorduras constituintes de alimentos industrializados 
(bolacha recheada, biscoito doce, salgadinho, refrigerante, suco de caixinha, chocolate, barra de cereal, queijo petit suisse, macarrão instantâneo, entre outros), a partir de suas respectivas tabelas nutricionais, e foram dispostas as quantidades de açúcar e gordura em recipientes separados, para que assim as pessoas tivessem a real visão da quantidade desses ingredientes. Esses alimentos e recipientes foram expostos em uma mesa para que os participantes tivessem uma melhor visualização. A fim de conscientizar sobre os riscos que esses tipos de alimentos podem trazer à saúde, foi iniciada uma roda de conversa a respeito dos prejuízos do consumo excessivo dos mesmos e possíveis formas de substituição.

O consumo insuficiente de frutas e hortaliças, e o consumo excessivo de alimentos ricos em gorduras e açúcares estão associados ao desenvolvimento e ao aumento da incidência de obesidade e de outras DCNT's"1. A oficina "Açúcares e gorduras" obteve grande impacto, evidenciando a surpresa e conscientização dos participantes visualizarem os alimentos com seus recipientes, pois mostrou fisicamente a quantidade destes compostos nos alimentos industrializados mais comuns que fazem parte da alimentação da população.

Referente a dinâmica "Alimentação saudável", foi realizada uma roda de conversa com os participantes e, por meio de perguntas, foi conduzida a conversa sobre como a alimentação é capaz de impactar na qualidade de vida a longo prazo, bem como no aumento ou diminuição de risco de desenvolvimento de DCNT's. Abordou-se principalmente a temática de graus de processamento dos alimentos e seus impactos à saúde. Ao final do diálogo, foi oferecida aos participantes como opção de lanche uma maçã.

A rotina diária, a carga horária de trabalho estendida e os condicionantes sociais dificultam a obtenção de hábitos alimentares saudáveis, havendo uma modificação no padrão alimentar, onde os alimentos in natura ou minimamente processados foram sendo substituídos por produtos alimentícios ultraprocessados prontos para o consumo ${ }^{12}$. Diante disso, na oficina "Alimentação saudável" foram trabalhadas as escolhas alimentares adequadas, incentivando que os alimentos in 
natura ou minimamente processados sejam a base da alimentação ${ }^{8}$. Esta oficina despertou interesse dos participantes em razão de ter demonstrado a infinidade de opções saudáveis a serem escolhidas para uma refeição adequada, evitando os alimentos ultraprocessados.

Correspondente a dinâmica "Lanches saudáveis", foi preparado um mural comparativo contendo versões diferentes de lanches que podem ser consumidos entre as grandes refeições. Este mural continha opções de lanches saudáveis e também alimentos ultraprocessados comumente ingeridos pela população. Iniciouse uma roda de conversa, a fim de alertar sobre os malefícios à saúde do consumo de determinados alimentos, assim como os benefícios e a importância da ingestão de lanches saudáveis entre as principais refeições do dia.

De forma a orientar sobre o fracionamento das refeições ao longo do dia e melhor distribuição das calorias, foi aplicada a oficina "Lanches Saudáveis". Os lanches da manhã e da tarde podem ajudar a atender as necessidades energéticas diárias, fornecendo nutrientes essenciais. Houve uma explicação em relação às escolhas dos alimentos a serem consumidos, quais quantidades e os benefícios da sua ingestão. Este fato gerou surpresa entre os participantes, que compreenderam a importância das pequenas refeições e a adequada escolha dos alimentos que as compõem ${ }^{13}$.

Relativo à dinâmica "Comida de verdade" foi explicada a respeito dos graus de processamento dos alimentos, divididos em: in natura ou minimamente processados; processados; e ultraprocessados. Desta forma, os participantes foram divididos em grupos, para os quais foi disponibilizada uma cartela dividida em in natura ou minimamente processado, processado e ultraprocessado, correspondendo às cores verde, amarelo e vermelho, respectivamente (Figura 2). Assim como foram disponibilizadas imagens de alimentos, as quais poderiam ser encaixadas em cada categoria. Ao final, verificou-se a asserção de cada grupo, esclarecendo dúvidas dos participantes. Desta maneira, realizou-se rodízio das imagens de alimentos entre 
grupos, a fim de estimular a participação dos presentes e reafirmar o seu entendimento.

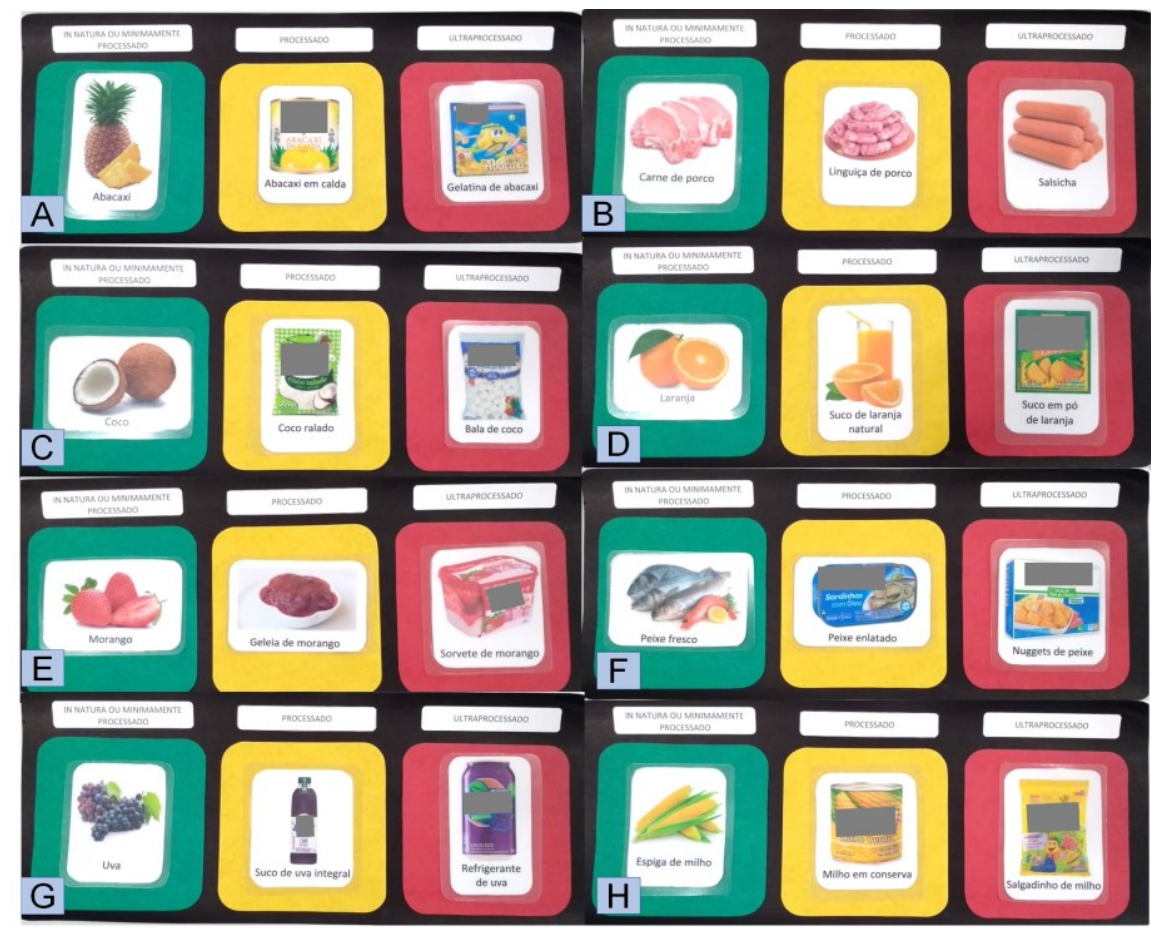

Figura 2. Cartelas utilizadas na dinâmica "Comida de verdade". Itajaí-SC, 2019.

Legenda: a imagem A demonstra os graus de processamento do abacaxi; a imagem B ilustra os graus de processamento da carne de porco; a imagem C ilustra os graus de processamento do coco; a imagem D revela os graus de processamento da laranja; a imagem E demonstra os graus de processamento do morango; a imagem $\mathrm{F}$ ilustra os graus de processamento do peixe; a imagem $G$ ilustra os graus de processamento da uva; a imagem $\mathrm{H}$ ilustra os graus de processamento do milho.

Uma alimentação diversificada, baseada em frutas, legumes e verduras está associada a diminuição de risco de desenvolvimento de DCNT's, sendo essencial para a homeostase do organismo. A oficina "Comida de verdade" foi direcionada para a orientação quanto ao grau de processamento dos alimentos, conscientizando para uma alimentação baseada em alimentos in natura ou minimamente processados $^{14}$. Ao terem o conhecimento dos graus de processamento e visualizarem a classificação de alguns alimentos, os participantes demonstraram surpresa, consequência de consumirem estes acreditando serem saudáveis, visto que a informação transmitida pela mídia induz o consumidor a compra de produtos ultraprocessados, geralmente ricos em gorduras, sódio e açúcares ${ }^{15}$. 
Na dinâmica "Benefícios da aveia e chia" foram abordadas as propriedades das fibras, utilizando como exemplo a aveia e a chia. Foi entregue aos participantes um folheto educativo explicando os potenciais benefícios à saúde desses dois alimentos e, a partir dele, foi iniciada uma roda de conversa. Foi disponibilizado ainda um segundo folheto contendo quatro receitas com utilização da aveia ou chia, a fim de exemplificar sua forma de uso.

A ingestão de fibras deve fazer parte das refeições visto que possui inúmeros benefícios para o funcionamento adequado do intestino, perfil lipídico, emagrecimento, controle da glicemia e saciedade. Objetivando demonstrar opções práticas de utilização e informar os benefícios, foi elaborada a oficina "Benefícios da aveia e chia", revelando interesse pelos participantes, uma vez que poderiam fazer uso e obter benefício destas fibras. Estes alimentos são de fácil aquisição, utilização e aceitação, sendo ideais para a complementação dos lanches saudáveis. Suas propriedades são justificadas pela sua composição, capacidade de hidratação e mucilagem ${ }^{16}$.

Para a dinâmica "Intestino saudável" foi utilizado um banner dividido em duas partes: uma contendo uma imagem relacionada ao trânsito intestinal normal e outra relacionada ao intestino preso. Com o auxílio de figuras de alimentos, foi perguntado aos participantes se, de acordo com os seus conhecimentos, determinado alimento era benéfico ou agravante para a saúde intestinal, sendo explicado sobre cada alimento ao final. Posteriormente, foram expostos cartazes com as quantidades de fibras presentes em cada alimento e esclarecido a respeito da importância das mesmas para manter um trânsito intestinal normal. Foi apresentada ainda uma receita de biscoito caseiro (preparado com aveia e banana) como opção de substituição aos alimentos industrializados, pobres em fibras. Por fim, foi oferecido para degustação um bolo de aveia e banana aos participantes.

Segundo Sousa et al. ${ }^{17}$ a alimentação exerce grande papel na prevenção e/ou tratamento da constipação intestinal. As frutas, verduras e cereais integrais possuem um adequado aporte de fibras, que são os nutrientes importantes nesta condição. 
Além das fibras, são necessários também outros componentes como os prebióticos (compostos encontrados em alimentos de origem vegetal, não digeridos pelo intestino humano e fermentados pelos microrganismos do trato gastrintestinal). É essencial que haja uma ingestão hídrica adequada, pois esta auxilia na eliminação das fezes, deixando-as macias, facilitando os movimentos peristálticos, evitando ressecamento e consequente dificuldade de evacuar ${ }^{18}$. A partir disso, a oficina "Intestino saudável" retratou alguns alimentos que auxiliam na saúde intestinal, bem como os que prejudicam. Os participantes revelaram surpresa ao conhecer a função destes alimentos e a importância da sua ingestão em virtude de desconhecerem tais informações.

A dinâmica "Consumo hídrico" contou com o apoio de dois banners: um deles ilustrando, a partir da escala de urina, o grau de hidratação e também as quantidades necessárias de consumo de água diário ${ }^{19}$; e o outro ilustrando o funcionamento do corpo humano por meio dos benefícios do consumo hídrico (Figura 3). Esses banners auxiliaram para que houvesse uma discussão e indagações pelos participantes, gerando uma roda de conversa. Por meio dessas argumentações e também de perguntas, foi possível explanar a importância do consumo hídrico e seus benefícios ao organismo, de maneira coloquial. Ao final da dinâmica, foi oferecido aos participantes uma degustação de água saborizada com laranja, hortelã e abacaxi. 


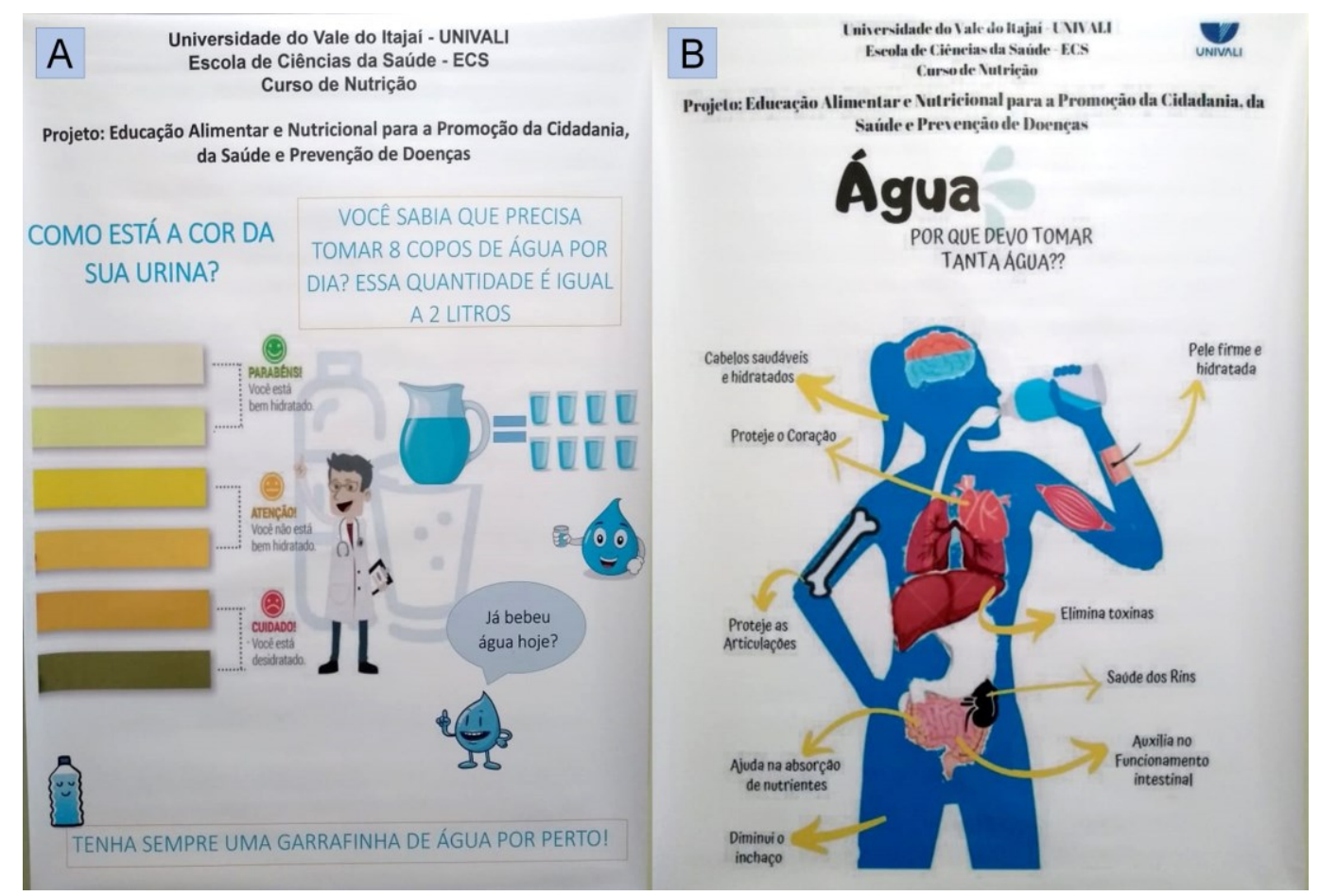

Figura 3. Banners utilizados na dinâmica "Consumo hídrico". Itajaí-SC, 2019.

Legenda: a imagem A demonstra o primeiro banner expondo a escala de coloração de urina, bem como a necessidade diária de água; a imagem $\mathrm{B}$ demonstra o segundo banner ao qual dispõe sobre os benefícios do consumo hídrico.

A água é um componente essencial para a manutenção de todos os sistemas do organismo, possui papel fundamental na regulação das funções corporais, incluindo a regulação da temperatura, transporte de nutrientes e eliminação de substâncias indesejáveis. Deve estar aliada a uma alimentação equilibrada e o consumo deve ser de água, não contabilizando chás, cafés, sucos e outros líquidos. Diante disso, a oficina "Consumo hídrico" abordou aspectos sobre a importância do consumo de água no dia a dia, bem como os sintomas da desidratação, esclarecendo suas funções diante de todos os sistemas, tendo conscientização e preocupação por parte dos participantes, que revelaram não consumir água suficiente ao longo do dia $^{8}$.

A respeito da dinâmica "Chás", foram distribuídos em trouxinhas de TNT ervas secas (hortelã, erva-cidreira, espinheira-santa e hibisco), para que não fosse possível identificar quais eram. A partir disso, os participantes foram convidados a identificar qual erva pertencia a cada saquinho por meio do olfato e tato. Após essa 
percepção, foi dialogado sobre as propriedades de cada planta, a fim de esclarecer dúvidas, enaltecer conhecimentos populares e desmistificar possíveis equívocos de utilização.

Para Balbinot, Velasquez e Düsman ${ }^{20}$ o consumo de chás tem base na tradição familiar e tornou-se prática generalizada na medicina popular, sendo considerada uma terapia complementar ou alternativa para a promoção da saúde. Assim o conhecimento das recomendações terapêuticas das plantas medicinais é, normalmente, uma característica presente na população em geral. Sentindo a necessidade de informar, devido ao fato de ser altamente consumido pela população, foi elaborada a oficina “Chás", que contou com a efetiva cooperação dos participantes em razão de possuírem conhecimento prévio sobre o assunto. É de grande relevância que se saiba reconhecer as diferenças sensoriais e as propriedades destas plantas considerando que existe toxicidade e contraindicações.

Na dinâmica "Alimentos que melhoram o astral" foi realizado um bingo dos alimentos, onde foram distribuídas cartelas de bingo intercalando números e alimentos, podendo ser sorteado um número ou um alimento. Ao sortear um alimento, eram expostas breves explicações sobre os benefícios do seu consumo em relação à melhora do humor. Ao preencher a cartela completa, o participante era premiado com uma cesta de frutas.

A depressão é uma doença multifatorial e um dos principais sintomas é o humor deprimido e a perda de interesse na realização de atividades. A dieta influencia diretamente na produção de neurotransmissores influenciadores do humor e comportamento (serotonina e dopamina), sendo que o consumo de alimentos ricos em triptofano, tirosina e histidina (aminoácidos) é um meio de alterar parcialmente o metabolismo dos neurotransmissores. Dessa forma, para combater as carências alimentares é de extrema importância uma boa orientação nutricional. Na oficina "Alimentos que melhoram o astral" foram apresentadas opções alimentares com potencial de influenciar positivamente no bom humor, bem- 
estar, sono, ansiedade e estresse, provocando grande animação entre os participantes que desconheciam a influência da alimentação neste aspecto ${ }^{21}$.

Sobre a dinâmica "Rótulos alimentares" foi utilizado um banner contendo um comparativo de dois rótulos de uma mesma categoria de alimento, sendo o macarrão instantâneo e o macarrão convencional (Figura 4). Dessa forma, os mesmos apresentavam a tabela nutricional, lista de ingredientes, preços e uma sugestão de molho de tomate caseiro para o macarrão convencional em substituição ao tempero pronto do macarrão instantâneo. A partir deste material, foi iniciada uma explicação a respeito dos rótulos, a fim de ensinar como interpretar os mesmos e poder, assim, ter maior autonomia na escolha dos alimentos. Foram disponibilizados, ainda, rótulos físicos de alimentos com suas respectivas tabelas nutricionais e lista de ingredientes na forma de cartões, facilitando a visualização, uma vez que as fontes das letras dos rótulos são pequenas. Os escolhidos foram: néctar de uva em lata e suco de uva integral; molho de tomate pronto e extrato de tomate; leite integral UHT e leite em pó; iogurte natural e bebida láctea fermentada.

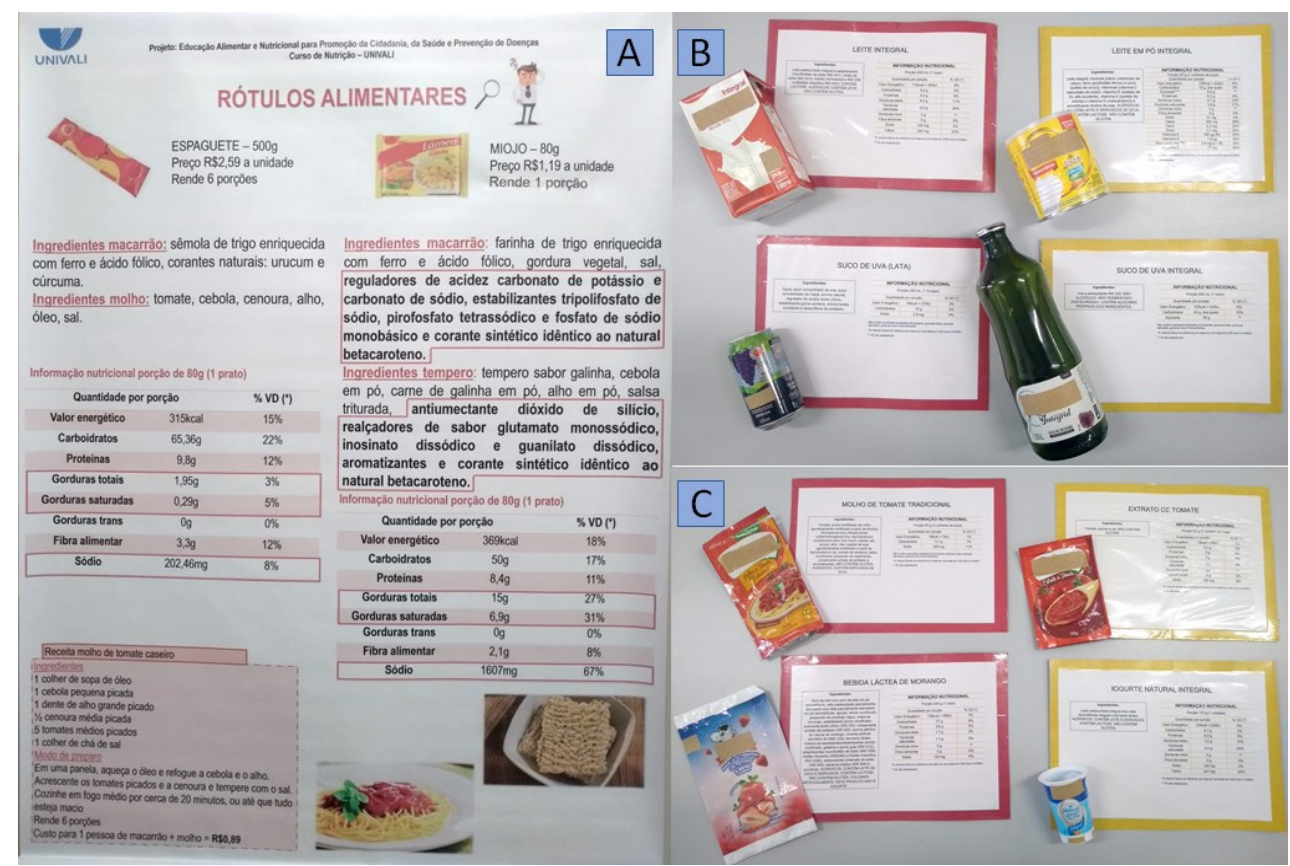

Figura 4. Materiais utilizados na dinâmica "Rótulos alimentares". Itajaí-SC, 2019.

Legenda: a imagem A demonstra o banner utilizado para explicação de diferentes alimentos industrializados; as imagens B e C ilustram de maneira ampliada os rótulos de seus respectivos alimentos. 
O conjunto de informações apresentadas nos rótulos dos alimentos tem sido visto como um importante instrumento para a promoção da saúde e redução do risco de desenvolvimento das DCNTs. Essas informações exercem um papel educativo na definição de hábitos alimentares. Nesse sentido, é importante incentivar o hábito de leitura dos rótulos alimentares, a identificação de ingredientes incomuns, a conscientização da compra somente após uma avaliação criteriosa do produto e promoção da autonomia do consumidor na hora da escolha. Na oficina "Rótulos alimentares" foi apresentado um banner explicativo fazendo uma comparação entre rótulos de dois tipos de macarrão (um instantâneo e outro tradicional), de forma a evidenciar a importância da sua interpretação. No decorrer da oficina foi observado que os participantes demonstraram surpresa ao conhecer a função do rótulo e a quantidade de informações que podem ser apresentadas. Além disso, manifestaram ter obtido autonomia para a escolha dos alimentos, pois com o aprendizado poderiam optar por opções alimentares de forma consciente ${ }^{14}$.

Na dinâmica "PANC's", o objetivo foi proporcionar informação e conhecimento a respeito de como identificar as plantas alimentícias não convencionais. Para efetivação da oficina, foram utilizados vasos de amora e orapro-nóbis, realizando-se uma roda de conversa, evidenciando maneiras de identificação, formas de utilização e seus potenciais benefícios. Além disso, foi entregue um folheto educativo e amostras de erva baleeira. Ao final, foi oferecido aos participantes uma degustação de "Pão de queijo de taioba".

No Brasil existem pelo menos 3 mil espécies de PANC's documentadas, destacando a necessidade de ações educativas que informem seus benefícios e toxicidade, bem como sua identificação. Elas são plantas que possuem potencial alimentício e desenvolvimento espontâneo, podendo ser nativas ou exóticas, geralmente sendo confundidas com ervas daninhas. São chamadas não convencionais por não serem consumidas em grande quantidade, ou por serem utilizadas apenas em diferentes regiões. A oficina "PANC's" objetivou proporcionar conhecimento das diversas propriedades e aplicações culinárias destas plantas. Nesta oficina, houve maior cooperação pelos participantes uma vez que já 
dispunham de conhecimento prévio acerca do assunto, participando ativamente e compartilhando suas experiências pessoais com estas plantas ${ }^{10}$.

Quanto a dinâmica "Festa junina saudável", foram abordadas opções de modificações de receitas tradicionais desta época do ano por opções saudáveis, por meio de uma roda de conversa com os participantes, discutindo os benefícios dessas substituições, bem como os malefícios dos alimentos típicos desta festa, uma vez que são ricos em açúcares e gorduras. Houve ainda a entrega de um folheto contendo duas receitas (bolo de fubá e chá de maçã com especiarias) e degustação de pipoca funcional com alecrim e cúrcuma.

As preparações típicas da Festa Junina são ricas em açúcares, sal e gorduras, uma vez que estes produtos são utilizados para deixar a preparação agradável ao paladar. Estes produtos alimentícios com alto teor de carboidrato, sódio e lipídios respectivamente, sendo que o consumo excessivo é prejudicial à saúde, estando associados ao aumento do risco de desenvolvimento de cárie dental, obesidade, dislipidemias e outras DCNT's. Além disso, as gorduras e açúcares possuem elevada quantidade de calorias por grama, consideradas "vazias" por não fornecerem nutrição ao organismo. Tendo em vista os aspectos culturais locais e regionais, foi elaborada a oficina "Festa junina saudável", que trabalhou a conscientização para as trocas das receitas tradicionais por opções adaptadas, diminuindo as calorias vazias e agregando aporte nutricional às preparações. Os participantes se mostraram animados com a possibilidade de manter a tradição e aliar ingredientes saudáveis deixando as preparações saborosas e nutritivas ${ }^{8}$.

\section{Conclusões}

Os três pilares da universidade são Pesquisa, Ensino e Extensão, conjunto que possibilita o completo aprendizado e experiência aos acadêmicos. A oportunidade de atuação em um projeto de extensão universitária proporciona experiências únicas que não são adquiridas em sala de aula. Promove o estreitamento dos laços entre 
universitários e comunidade, tornando-os profissionais aptos a praticar a empatia e sensibilidade social, tão importante ao profissional da saúde.

A vivência nas ações também possibilitou uma maior interação e troca de conhecimentos entre professores e acadêmicos, os quais foram fundamentais na orientação do planejamento, elaboração e aplicação do material educativo desenvolvido em conjunto com os alunos.

No decorrer das ações houve certa dificuldade de conquistar e manter a atenção dos participantes do grupo, devido ao grande número de atividades desenvolvidas no local por acadêmicos de outros cursos, além das demais atividades já programadas pelos próprios espaços para entreter os frequentadores, como a realização de bingos. No entanto, a maioria dos participantes cooperou durante a prática das atividades, demonstrando interesse e gratidão pelo aprendizado, atingindo o objetivo das ações.

Portanto, a participação em um projeto de extensão incentiva os integrantes do projeto a aproximar-se da realidade da sociedade, desafiando-o a enfrentar obstáculos e superar dificuldades juntamente com a comunidade beneficiária. Da mesma forma, contribui para a autonomia dos indivíduos, aprendizagem acerca da alimentação saudável e melhora da qualidade de vida.

\section{Referências}

1. Dias PC, Henriques P, Anjos LA, Burlandy L. Obesidade e políticas públicas: concepções e estratégias adotadas pelo governo brasileiro. Cad Saúde Pública 2017; 33(7): e00006016.

2. Silva FM, Gonçalves LG, Figueiredo RC, Barreto SM, Consumo de alimentos ultraprocessados, IMC e circunferência da cintura no ELSA-Brasil. X Congresso Brasileiro de Epidemiologia 2017. Campinas: Gaolá; 2018.

3. Castro IRR. A extinção do Conselho Nacional de Segurança Alimentar e Nutricional e a agenda de alimentação e nutrição. Cad Saúde Pública 2019; 35(2): e00009919.

4. Vicenzi K, Henn RL, Weber AP, Backes V, Paniz VMV, Donatti T, et al. Insegurança alimentar e excesso de peso em escolares do primeiro ano do 
Ensino Fundamental da rede municipal de São Leopoldo, Rio Grande do Sul, Brasil. Cad Saúde Pública 2015; 31(5): 1084-1094.

5. Brasil. Política Nacional de Alimentação e Nutrição. 1 ed. Ministério da Saúde: Brasília 2013.

6. Oliveira EE. Um auto relato sobre a participação no projeto "Ateliê do sorriso": um caminho percorrido da extensão à sociedade. Rev Ciência Plural 2019; 5(3): 72-88.

7. Kuhn IN, Remi AD. Elaboração e acompanhamento de projetos públicos e sociais. 1 ed. Editora Unijuí: Rio Grande do Sul 2008.

8. Brasil. Guia Alimentar para População Brasileira. 2 ed. Ministério da Saúde: Brasília 2014.

9. Bezerra INM, Monteiro VCM, Nascimento JL, Vieira NRS, Silva RPC, Alcântara BDC, et al. Ações de educação em saúde e o planejamento familiar: um relato de experiência. Rev Ciência Plural 2018; 4(3): 82-90.

10. Liberato OS, Travassos DV, Silva GMB. PANCs: plantas alimentícias não convencionais e seus benefícios nutricionais. Environ. Smoke 2019; 2(2): $102-$ 111.

11. Barroso TA, Martins LB, Alves R, Gonçalves ACS, Barroso SG, Rocha GS. Associação entre a obesidade central e a incidência de doenças e fatores de risco cardiovascular. Int J Cardiovasc Sci 2017; 30(5): 416-424.

12. Santos DS, Carneiro MS, Silva SCM, Aires CN, Carvalho LJS, Costa LCB. Transição nutricional na adolescência: uma abordagem dos últimos 10 anos. Rev Eletrônica Acervo Saúde 2019; 20(20): 1-5.

13. Rodrigues TRA. A hora do Lanche: estratégias para a promoção de uma alimentação saudável e sustentável [dissertação]. Instituto Politécnico de Viana do Castelo: Escola Superior de Educação 2018.

14. Santos CMB, Araújo CC, Soares MB, Jesuino RSA, Morais CC. Experiência de extensão: "Rotulagem nutricional: conheça o que você consome". Rev Ciência em Extensão 2016; 12(4): 160-173.

15. Zagminan A, Moraes DM, Belfort IA, Dias LPP, Coimbra LMPL. Exposição a mídia e hábitos alimentares de adolescentes em uma escola privada de São Luís-MA. Rev Investigação Biomédica 2019.

16. Rocha, YMA, Silva LPE, Régis WCB. Chia (Salvia hispânica) benefits for human health: a review on clinical trials in humans. Percurso Acadêmico 2017; 7(14): 483-493.

17. Sousa VBB, Vasconcelos LPF, Araújo DGS, Lemos JOM, Medeiros LSM, Nogueira RBSS, et al. Constipação intestinal em crianças e a importância das fibras alimentares: uma revisão da literatura. Rev Eletrônica Acervo Saúde 2019; 21(21): 1-9. 
18. Boilesen SN, Tahan S, Dias FC, Melli LCFL, Morais MB. Ingestão de água e líquidos na prevenção e no tratamento da constipação intestinal funcional em crianças e adolescentes: existem evidências?. J Pediatr 2017; 93(4): 320-327.

19. Armstrong LE, Maresh CM, Castellani JW, Bergeron MF, Kenefick RW, Kent ELG, et al. Urinary indices of hydration status. Int J of Sport Nutrition 1994; 4(3): 265-279.

20. Balbinot S, Velasquez PG, Düsman E. Reconhecimento e uso de plantas medicinais pelos idosos do Município de Marmeleiro - Paraná. Rev Bras Plantas Medicinais 2013; 15(4): 632-638.

21. Henn R, Almeida EB, Guedes MR, Santos ACC, Ott APC, Vargas AJ, et al. Educação alimentar e nutricional para grupos vulneráveis: um relato de experiência das vivências de extensão universitária. Rev Bras Tecnologias Sociais 2018; 5(1): 59-68. 